\title{
VALIDATION OF LEAD (Pb) ANALYSIS METHOD IN FISH MEAL MATRIX BY ELECTROTHERMAL ATOMIC ABSORPTION SPECTROPHOTOMETRY
}

\author{
Suwari ${ }^{1 \rrbracket}$, Sherlly M.F. Ledoh ${ }^{1 \rrbracket}$ (iD), and Philiphi de Rozari \\ ${ }^{1}$ Faculty of Science and Engineering, Nusa Cendana University, Jl. Adisucipto Kampus Baru Penfui, Kupang, \\ NTT 85361, Indonesia.
}

\section{ABSTRACT}

Received 25 July 2021

Accepted 11 August 2021

Published 07 September 2021

CorrespondingAuthor

Suwari, suwari_chem68@yahoo.com DOI 10.29121/IJOEST.v5.i5.2021.215

Funding: This research received no specific grant from any funding agency in the public, commercial, or not-for-profit sectors.

Copyright: (C) 2021 The Author(s). This is an open access article distributed under the terms of the Creative Commons Attribution License, which permits unrestricted use, distribution, and reproduction in any medium, provided the original author and source are credited.

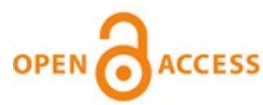

Validation of analytical methods is the process of proving that the methods used are scientifically good and suitable for certain purposes. The aim of this study was to validate the analytical method of lead in fish meal matrix by electrothermal atomic absorption spectroscopy (ETAAS) using a phosphate modifier. The research begins with optimization of the analytical conditions that include pyrolysis (ashing) and atomizing temperature, and continues with the validation process by evaluating the analytical performance parameters using a certified reference material (CRM). Method validation was carried out by determining the level of accuracy and precision as well as lead content in a CRM Cod Muscle-422 from BCR. Each experiment was conducted at a wavelength of $283.3 \mathrm{~nm}$, a lamp current of 9.0 amperes, a slit width of $1.3 \mathrm{~nm}$ and an argon carrier gas. The optimal pyrolysis and atomizing temperature of lead obtained by adding phosphate modifier was $650^{\circ} \mathrm{C}$ and $2000^{\circ} \mathrm{C}$, respectively. The results obtained in this study indicate that the ETAAS lead analysis method using a phosphate modifier is feasible as a test method with an RSD of $3.79 \%$, precision of 0.0043 , relative error of $4.0 \%$, accuracy of $104 \%$ and recovery of $98 \% \pm 3 \%$. The results of the validation method obtained that the $95 \%$ confidence interval for $\mathrm{Pb}$ content was $0.088 \pm 0.023 \mu \mathrm{g} / \mathrm{g}$, still within the range of Pb levels in the certificate, namely $0.085 \pm 0.015 \mu \mathrm{g} / \mathrm{g}$ of $\mathrm{Pb}$.

Keywords: Validation, CRM, Cod Muscle, ETAAS, Lead

\section{INTRODUCTION}

Analysis of the content of hazardous and toxic substances in food ingredients and products plays an important role in ensuring product quality and consumer protection as well as for the development of health and nutrition programs in Indonesia. Therefore, the analytical equipment and methods used must have high sensitivity, precision and accuracy, so that the validity of the analysis results is guaranteed.

Among the food contaminants, lead $(\mathrm{Pb})$ along with cadmium $(\mathrm{Cd})$ and mercury $(\mathrm{Hg})$ have received much attention. Lead is one of the most dangerous heavy metals for human health. The intake of $\mathrm{Pb}$ (II) cations in the body can affect kidney function, brain cells and liver membrane permeability. $\mathrm{Pb}$ accumulation in the body can cause nausea, vomiting, diarrhea, coma and death Shirkhanloo et al. (2014). Lead is generally found in food ingredients 
and products. at very low concentrations (trace) so that analysis of lead levels is difficult. In addition, matrix complexity, decomposition, presence of contaminants, and other procedural steps increase the problem of lead analysis complexity Yaman et al. (2000); Vinas et al. (2000); Turek et al. (2019).

In general, lead analysis uses the flame atomic absorption spectrometry (FAAS) method because of the fast analysis time and high precision, but the atomization efficiency is only $2 \%$ to $5 \%$ with a detection limit of 0.05 ppm Haswell (1991); Dulski (1999); Shirkhanloo et al. (2014). Meanwhile, the concentration of lead in food ingredients and products is generally very low, so an analytical method with a low detection limit and high sensitivity is needed.

The existence of the atomic absorption spectrometry method with the electrothermal atomization technique (ETAAS) has received much attention from researchers because this method offers high sensitivity. However, the matrix effect is quite large as a result the level of precision and accuracy of the analysis is still low He and Zhe-Ming. (1996); Zong et al. (1996); Bulska and Ruszczyńska (2017). Interference in ETAAS analysis can be eliminated if the pyrolysis temperature is high enough without loss of analyte. One simple way to eliminate interference is to use chemical modifiers. The use of a modifier will increase the volatility of the matrix and reduce the volatility of the analyte in the pyrolysis step, not reducing the life of the furnace and not increasing the background absorption.

The reliability and reliability of lead analysis with the ETAAS method can be validated based on the analysis performance parameters which include sensitivity, detection limit, quantization limit, precision, and accuracy. One of the samples that have criteria to test the validity of lead analysis using the ETAAS method is fish meal matrix. The main objective of this study was to determine the optimum pyrolysis and atomization temperatures and to validate the ETAAS method to analyze the lead content in the fish meal matrix.

\section{MATERIALS AND METHODS \\ 2.1. CHEMICALS AND RESEARCH EQUIPMENT}

Chemicals used in the research include: hydrofluoric acid ( HF) 40\%, hydrogen peroxide, nitric acid $\left(\mathrm{HNO}_{3}\right)$ 65\%, perchloric acid $\left(\mathrm{HClO}_{4}\right)$ 60\%, ammonium dihydrogen phosphate $\left(\mathrm{NH}_{4} \mathrm{H}_{2} \mathrm{PO}_{4}\right)$ 99.999\% (from Aldrich), standard solution $\mathrm{Pb}$ 1000 ppm (Kantako Chemical), Whatmann filter paper, Certified Reference Material (CRM) Cod Muscle No 422 (from BCR), Aquades and aquabides, while equipment used includes: measuring flask, volume pipette, goiter pipette, glass funnel, eppendorf pipette, analytical balance, polyethylene (PE) bottle, hot plate, oven, graphite tube, teflon bomb and Hitachi Model Z-5000 Atomic Absorption Spectrophotometer.

\subsection{FISH MEAL MATRIX}

The sample studied was cinchfish meal matrix. The process of making the fish meal matrix is as follows: the head of the cinchfish is removed and the entrails of the fish are removed and the fish is cut into two parts. The skin and bones of the fish are separated from the flesh using a deboner. The fish meat is then collected, wrapped in calico cloth and put in a centrifuge, mixed with water and the centrifuge is turned. Fish meat that has been washed and then crushed using a grinder to form small pellets then dried in a heater at a temperature of $40{ }^{\circ} \mathrm{C}$ for 18 hours. After drying, the pellets were crushed again with a grinder to a size of \pm 200 mesh. 


\subsection{SAMPLE DESTRUCTION}

The sample destruction method adapts the method used by Okamoto and Fuwa. (1984) and Master et al. (1999). Weighed \pm 0.3 grams of the sample carefully and put it in a teflon vessel, then added $3 \mathrm{~mL}$ of $65 \% \mathrm{HNO}_{3}$. The cover and coat are put on, then the Teflon bomb is placed in the oven. The Teflon bomb was heated at $90{ }^{\circ} \mathrm{C}$ for 2 hours and then $140{ }^{\circ} \mathrm{C}$ for 4 hours. The solution in the Teflon bomb was cooled overnight, the next day it was opened and the steam was released until the color of the solution became greenish yellow. The greenish yellow solution in the Teflon bomb was then heated to a volume of $0.5 \mathrm{~mL}$ and then $0.6 \mathrm{~mL}$ of $\mathrm{HF}$ was added, heated again to a volume of $0.5 \mathrm{~mL}$. It was cooled for a while, then $0.5 \mathrm{~mL}$ of $\mathrm{HClO}_{4}$ was added and heated again until white steam appeared, then $0.5 \mathrm{~mL}$ of $65 \% \mathrm{HNO}_{3}$ was added. Reheated to a final volume of $0.5 \mathrm{~mL}$. After cooling, filtered with Whatmann filter paper No. 42, put in a $10 \mathrm{~mL}$ volumetric flask and diluted to the mark with distilled water.

\subsection{ANALYSIS CONDITIONS}

A total of $20 \mathrm{~L}$ of sample solution and $20 \mathrm{~L}$ of chemical modifier solution were injected into the graphite furnace and then heated according to the graphite furnace optimization temperature program which included the pyrolysis and atomization temperature. The lead content analysis was carried out at a wavelength of $283.3 \mathrm{~nm}$, a lamp current of 9.0 amperes, a slit width of $1.3 \mathrm{~nm}$ and an argon carrier gas.

\subsection{GRAPHITE FURNACE OPTIMIZATION}

Graphite furnace optimization includes finding the optimal pyrolysis and atomization temperature conditions. Optimization of pyrolysis and atomization temperature for lead content analysis was carried out by measuring the standard solution of $40 \mathrm{ppb}$ lead and sample solution from the destruction of fish meal matrix at several different temperatures using the $0.5 \% \mathrm{w} / \mathrm{v}$ of $\mathrm{NH}_{4} \mathrm{H}_{2} \mathrm{PO}_{4}$ modifier. The optimum pyrolysis (ashing) and atomizing temperature are determined by plotting the absorption versus the pyrolysis or atomizing temperature.

\subsection{VALIDATION USING CERTIFIED REFERENCE MATERIALS}

The lead analysis performance of ETAAS method was validated by testing the lead content of the CRM Cod Muscle-422 destruction solution at optimum conditions with 9 repetitions. Lead content in CRM is calculated by regression equation and calibration curve. The analysis performance of this steps is evaluated based on the precision and accuracy of the method.

\section{RESULT AND DISCUSSION \\ 3.1. EFFECT OF CHEMICAL MODIFIER ON PYROLYSIS TEMPERATURE}

In the analysis with ETAAS method, the main purpose of using chemical modifiers is to increase the pyrolysis temperature and minimize matrix interference. Therefore, effectiveness of chemical modifier is directly related to the stability effect. In this study, effect of pyrolysis temperature on lead absorbance using a phosphate modifier was tested by varying the pyrolysis temperature from $400{ }^{\circ} \mathrm{C}$ to $800{ }^{\circ} \mathrm{C}$ and atomization temperature was maintained at $2300{ }^{\circ} \mathrm{C}$. Results of the optimization of pyrolysis temperature in the $\mathrm{Pb}$ standard solution and fish meal digestion solution are shown in Figure 1. 


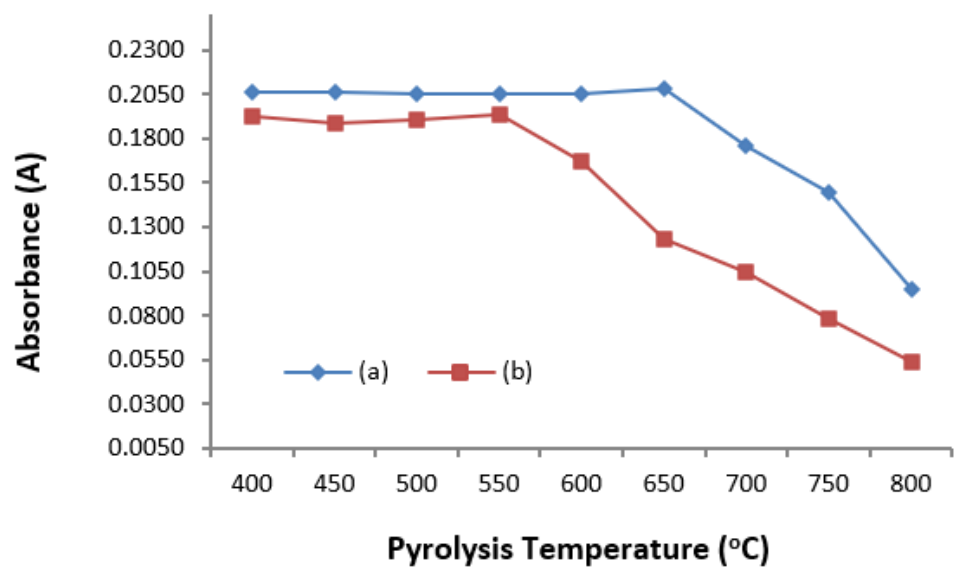

(1)

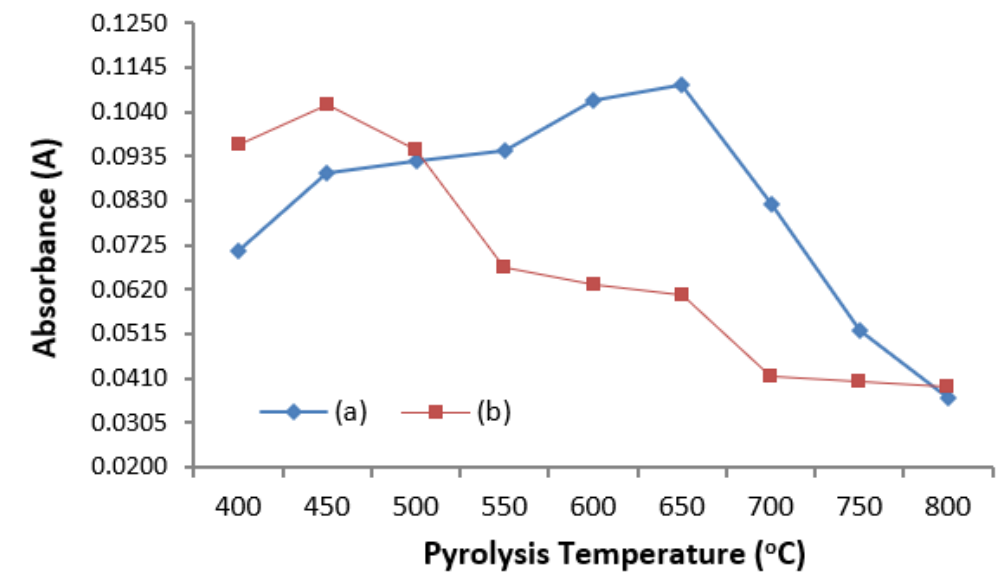

(2)

Figure 1 Lead absorbance as a function of pyrolysis temperature: (a) Phosphate Modifier, (b) Without Modifier (TM). Each symbol represents 2-3 injections: (1) standard solution $40 \mathrm{ppb}$ of Pb, (2) sample solution of fish meal which was destroyed by Teflon bomb.

The absorbance of the lead standard solution was significantly decreased at temperatures above $550{ }^{\circ} \mathrm{C}$ in the absence of chemical modifiers. This is probably due to the partial evaporation of lead during the pyrolysis step. On the other hand, in the presence of a phosphate modifier, the pyrolysis temperature can be increased to $650{ }^{\circ} \mathrm{C}$ without loss of analyte. Meanwhile, the pyrolysis temperature of the fish meal sample solution from the destruction was $650^{\circ} \mathrm{C}$ and $450{ }^{\circ} \mathrm{C}$ in the presence of a phosphate modifier and without a chemical modifier without loss of analyte. The results of this study indicate that the effect of phosphate modifier in stabilizing lead in fish meal matrix is quite good.

\subsection{EFFECT OF CHEMICAL MODIFIERS ON ATOMIZATION TEMPERATURE}

The effect of using chemical modifier on lead atomization temperature was tested by varying the atomization temperature from $1800{ }^{\circ} \mathrm{C}$ to $2500{ }^{\circ} \mathrm{C}$ using the optimum pyrolysis temperature. The results of the optimization of the atomization temperature are shown in Figure 2. 


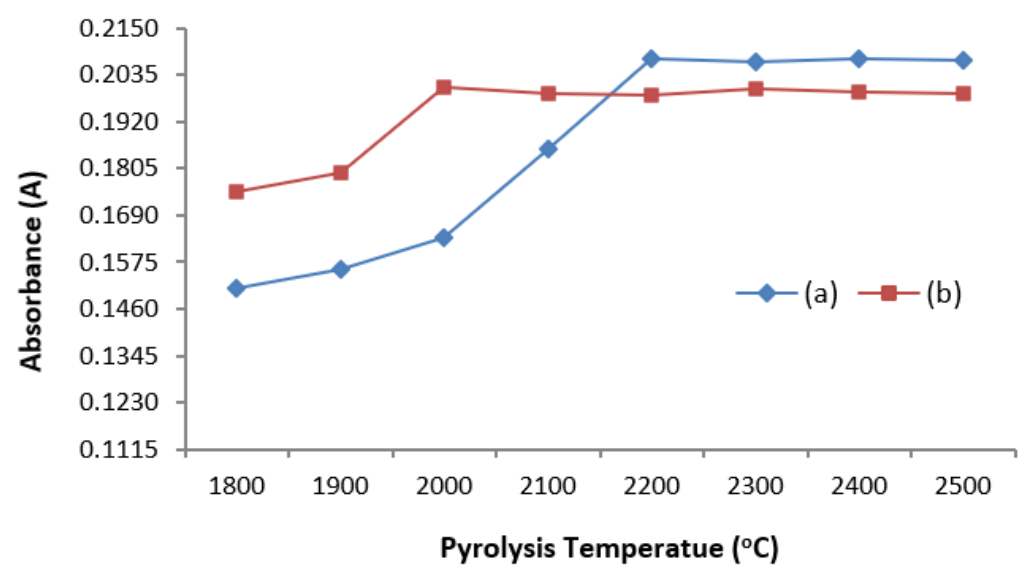

(1)

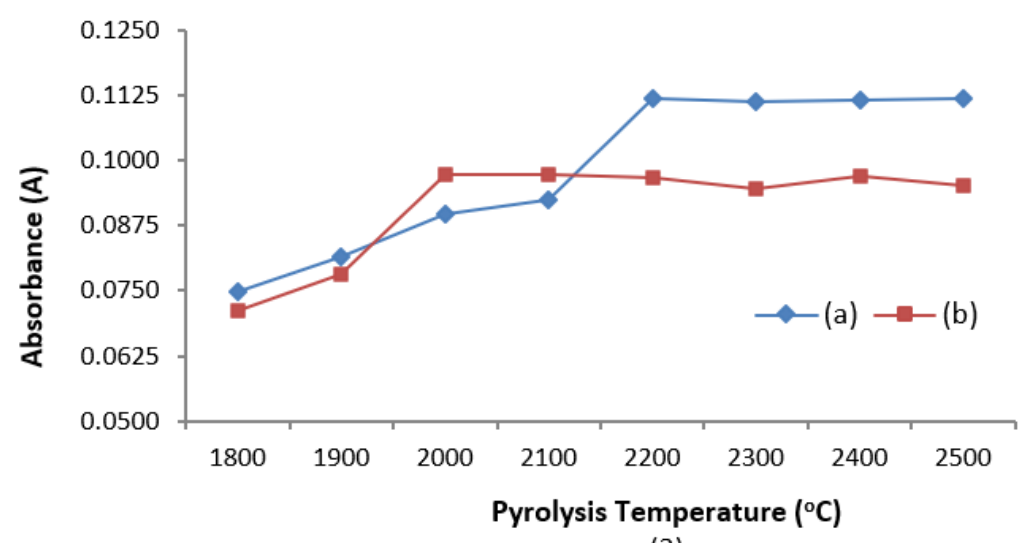

(2)

Figure 2 Lead absorbance as a function of atomization temperature: (a) Phosphate Modifier, (b) Without Modifier. Each symbol represents 2-3 injections: (1) standard solution $40 \mathrm{ppb}$ of $\mathrm{Pb},(2)$ sample solution of fish meal which was destroyed by Teflon bomb.

Lead atomization temperature ranges from 2200 to $2500{ }^{\circ} \mathrm{C}$ (using modifier) and 2000 to $2100^{\circ} \mathrm{C}$ (without a modifier). The relatively constant absorbance of lead and high reproducibility is achieved at atomization temperatures between $2000{ }^{\circ} \mathrm{C}$ and $2500{ }^{\circ} \mathrm{C}$. Therefore, taking into account the lifetime of the graphite tube, atomization temperatures selected are $2200{ }^{\circ} \mathrm{C}$ (with modifier) and $2000{ }^{\circ} \mathrm{C}$ (without modifier). The optimum analytical conditions proposed for the determination of lead in the fish meal matrix by ETAAS are shown in Table 1.

$\begin{aligned} & \text { Table } 1 \text { Instrumental parameters and results of optimization of pyrolysis and atomizing } \\
& \text { temperature for the determination of lead in fishmeal matrix }\end{aligned}$
\begin{tabular}{lcccc}
\hline Start/End Temperature $\left({ }^{\circ} \mathrm{C}\right)$ & $\begin{array}{c}\text { Ramp/Hold } \\
\text { Time (sec) }\end{array}$ & $\begin{array}{c}\text { Gas Flow } \\
(\mathrm{mL} / \mathrm{min})\end{array}$ \\
& $\begin{array}{c}\text { Phosphate } \\
\text { Modifier }\end{array}$ & without modifier & & \\
Drying & $80 / 140$ & $80 / 140$ & $40 / 0$ & 200 \\
\hline Pyrolysis (Ashing) & 650 & 450 & $20 / 0$ & 200 \\
\hline Atomization & 2200 & 2000 & $0 / 5$ & 0 \\
\hline Cleaning & 2650 & 2650 & $0 / 4$ & 200 \\
\hline Cooling & $0 / 0$ & $0 / 0$ & $0 / 17$ & 200 \\
\hline
\end{tabular}




\subsection{CALIBRATION CURVE}

The calibration curve was made by measuring the absorption of a number of standard solutions of $\mathrm{Pb}$ with concentrations of: 10, 20, 30, 40, 60, 80, and $100 \mathrm{ppb}$. Absorption measurements were carried out using the analytical conditions listed in Table1. Each standard concentration of lead was measured 3 times with an injection volume of $20 \mathrm{~L}$. Standard calibration curves are created with plotting the concentration of $\mathrm{Pb}$ standard solution (x-axis) and absorbance (y-axis), then point are connected by a straight line. The calibration curve obtained can be seen in Figure 3.

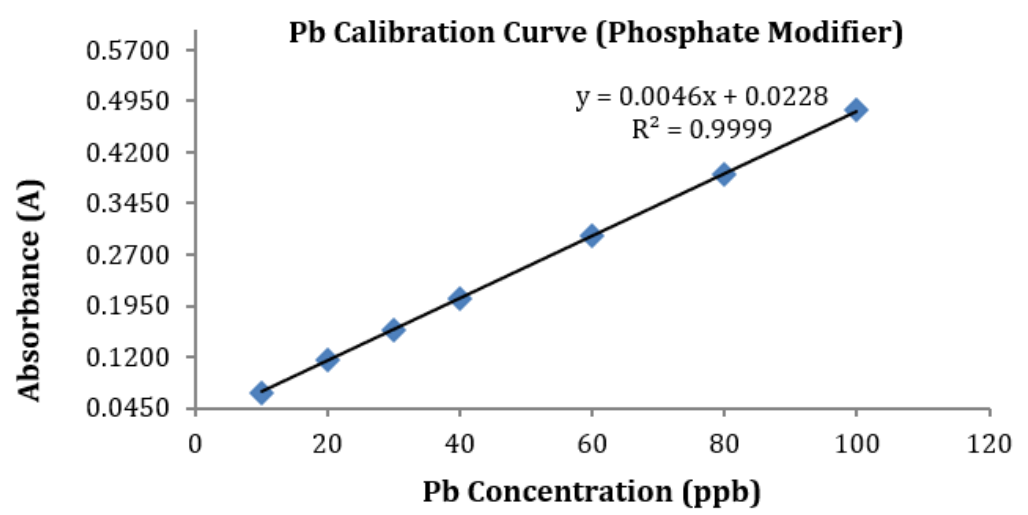

(1)

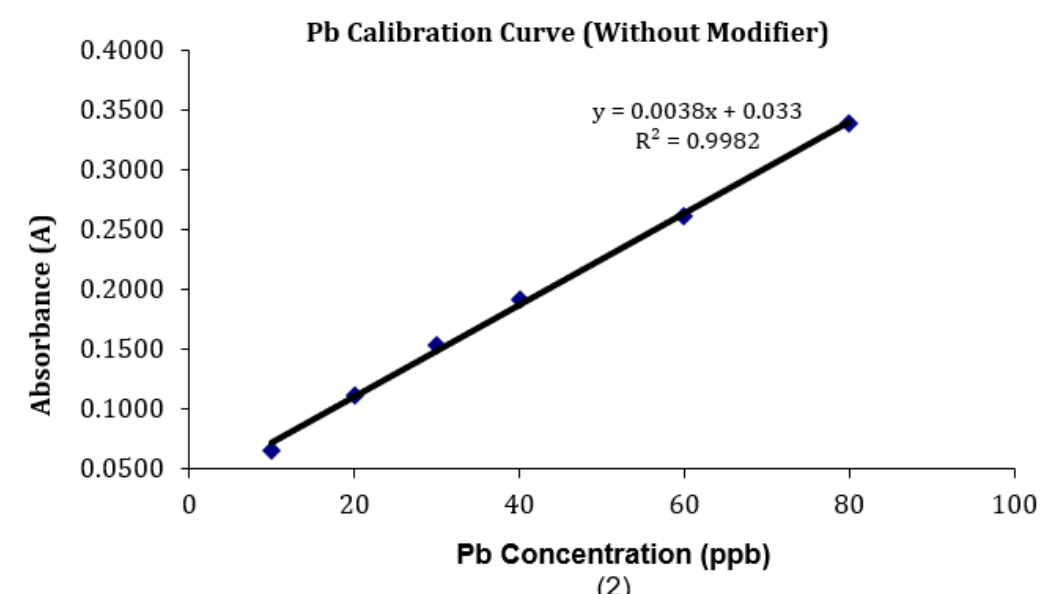

(2)

Figure 3 Calibration curve of a standard solution of Pb: (1) Phosphate Modifier (2) Without Modifier

The calibration curve obtained by the proposed procedure is linear up to $2 \mathrm{ng}$ mass $\mathrm{Pb}$ with a phosphate modifier and 1.6 ng mass $\mathrm{Pb}$ without a modifier. Regression equation obtained from the calibration curve of the $\mathrm{Pb}$ standard solution using a modifier (Equation 1) and without a modifier (Equation 2) is as follows:

$$
\begin{array}{lr}
Y=0,004577 X+0,022784 & \text { Equation 1 } \\
Y=0,003841 X+0,032960 & \text { Equation 2 }
\end{array}
$$

Estimation of the cut-off point confidence is tested from the intercept on the calibration curve. Test results obtained 95\% confidence limits for a (intercept) are 0.02048 to 0.02508 (with modifier) and 0.02235 to 0.04357 (without modifier), 
while the confidence level for b (slope) was 0.00454 to 0.00462 (with modifier) and 0.00361 to 0.00407 (without modifier).

\subsection{VALIDATION USING CRM COD MUSCLE-422}

The performance parameters of lead analysis in fish meal matrix by ETAAS, especially the level of accuracy of the method were tested using Certified Reference Material (CRM) Cod Muscle-422 from the Community Bureau of Reference (BCR). Method destruction of fish meal matrix samples was also applied to CRM. A total of 0.3014 grams of CRM Cod Muscle- 422 was digested by wet process using a Teflon bomb to obtain a solution ready for analysis as much as $10 \mathrm{~mL}$. Solution resulting from the digestion was analyzed by ETAAS using the $\mathrm{NH}_{4} \mathrm{H}_{2} \mathrm{PO}_{4}$ modifier with 9 replications under optimum conditions. Results measurement of $\mathrm{Pb}$ absorbance in the CRM solution and the Pb concentration calculated using Equation 1 are shown in Table 2.

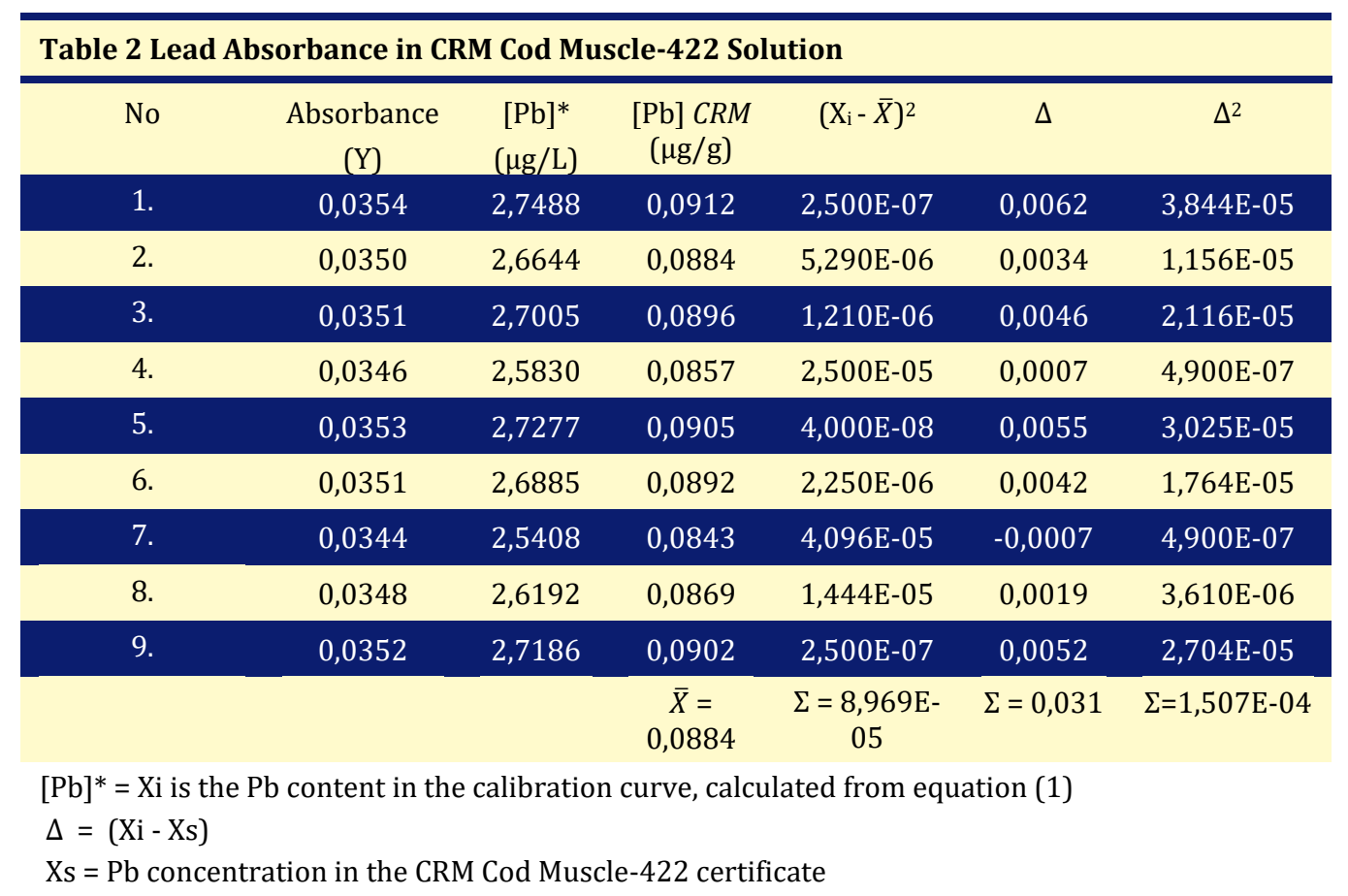

The $\mathrm{Pb}$ level in the Cod Muscle-422 reference material certificate is $0.085 \pm$ $0.015 \mu \mathrm{g} / \mathrm{g}$. Based on the data (Table 2), the standard deviation (s), RSD and accuracy of the method can be calculated as follows Caulcutt and Boddy. (1983), Miller and Miller. (1991), Skoog et al. (1996):

1) Standard deviation $(\mathrm{s})=\sqrt{\frac{\sum\left(X_{i}-\bar{X}\right)^{2}}{n-1}}=\sqrt{\frac{8.969 E-05}{8}}=0.0033$

2) Relative Standard deviation (RSD) $=\frac{s}{\bar{X}} \times 100 \%=\frac{0.0033}{0.0884} \times 100 \%=3.788 \%$

3) Precision $=\sqrt{\frac{\sum\left(X_{i}-X S\right)^{2}}{n-1}}=\sqrt{\frac{(1.507 E-04)}{8}}=0.0043$

4) Relative Error $(\% \mathrm{E})=\frac{|\mu-\bar{x}|}{\mu} \times 100 \%=\frac{|0.0850-0.0884|}{0.0850} \times 100 \%=4.0 \%$

5) Accuracy $=\frac{\bar{X}}{X_{S}} \times 100 \%=\frac{0.0884}{0.085} \times 100 \%=104 \%$

6) $95 \%$ confidence interval for $[\mathrm{Pb}]=\bar{X} \pm t . s / \sqrt{n}=0.088 \pm 0.023$ 
Precision and accuracy are the main criteria selected in validating a method. Based on results testing of Pb levels in the CRM Cod Muscle-422, it can be seen that $\mathrm{Pb}$ levels of the test results are within the range of $\mathrm{Pb}$ concentrations stated in the reference standard certificate. Thus, the ETAAS analysis method for lead in fish meal matrix has a good level of precision and accuracy.

The recovery test was also carried out to validate the accuracy of the method. It was carried out by measuring absorption 6 times from the sample solution to which $0.4 \mu \mathrm{g}$ of lead standard solution was added before being digested. By comparing the absorption values before and after the addition of a standard solution of $\mathrm{Pb}$, it can be seen the percentage of recovery. The test results show that the percentage of recovery $(\% \mathrm{R})$ was $98 \% \pm 3 \%$. According to Garcia-Alegria et al. (2015), a method has a high accuracy if the recovery ranges from $95 \%$ to $105 \%$.

The validated method was applied to analyze the lead content in the fish meal matrix. A total of 6 replicas of the fish meal matrix were digested by wet method in a Teflon vessel using nitric acid, hydrofluoric acid, and perchloric acid as solvents. The results of the analysis showed that $\mathrm{Pb}$ content in the fish meal matrix was 0.81 $\pm 0.08 \mu \mathrm{g} / \mathrm{g}$. Based on the Indonesian National Standard (2009) the maximum limit of lead contamination in fish and its processed products is $0.3 \mu \mathrm{g} / \mathrm{g}$.

\section{CONCLUSION}

The method of electrothermal atomic absorption spectrophotometry with phosphate modifier has good validity for analyzing lead content in foodstuffs and their products with complex matrices such as fish meal. Analysis performance parameters such as accuracy, precision and recovery were verified using a certified reference material (CRM) Cod Muscle-422 from BCR. Based on the parameters of accuracy, precision and recovery, the ETAAS method with phosphate modifier meets the requirements and deserves to be used as a test method.

\section{REFERENCES}

Bulska, E., and Ruszczyńska, A. (2017). Analytical Techniques for Trace Element Determination, Physical Sciences Reviews, 20178002. DOI: 10.1515/psr2017-8002. Retrieved from https://doi.org/10.1515/psr-2017-8002

Caulcutt, R., P. Boddy. (1983). Statistics for Analytical Chemistry, Chapman and Hall, London-New York.

Garcia-Alegria, A.M., Gomez-Alvarez, A., Garcia-Rico, L., Serna-Felix, M. (2015). Validation of an Analytical Method to Quantify Serum Electrolytes by Atomic Absorption Spectroscopy. Acta Universitaria, 25(3): 3-12. Retrieved from https://doi.org/10.15174/au.2015.747

Haswell, S.J. (1991). Atomic Absorption Spectrometry, Theory, Design and Applications, Elsiever, Amsterdam.

He Bin \& Zhe-Ming Ni. (1996). Minimization of Sulfat Interference on Lead Atomization with Palladium-Strontium Nitrate as Chemical Modifier in Electrothermal Atomic Absorption Spectrometry, J. Anal. At. Spectrom., 11, 165-168. Retrieved from https://doi.org/10.1039/JA9961100165

Master, Z., M., Angelone. C., Brunori. C., Cresmisini. H. Muntau \& R. Morabito. (1999). Digestion Methods for Analysis of Fly Ash Samples by Atomic Absorption Spectrometry, Anal. Chim. Acta, 395, 157-163. Retrieved from https://doi.org/10.1016/S0003-2670(99)00342-6

Miller, J.C. \& J.N. Miller. (1991). Statistika Untuk Kimia Analitik, ITB, Bandung. 
Okamoto, K., K. Fuwa. (1984). Low-Contamination Digestion Bomb Method Using a Teflon Double Vessel for Biological materials, J. Anal. Chem., 56, 1758-1760. Retrieved from https://doi.org/10.1021/ac00273a058

Shirkhanloo, H., Sedighi, K. and Hassan, Z.M. (2014). Determination of Trace Amount of Lead in Industrial and Municipal Effluent Water Samples Based on Dispersive Liquid-Liquid Extraction, J. Mex. Chem. Soc., 58(2): 137-141. Retrieved from https://doi.org/10.29356/jmcs.v58i2.169

Skoog, D.A., D.M. West \& F.J. Holler. (1996). Fundamental of Analytical Chemistry, 7th Ed., Saunders College Publishing.

Standar Nasional Indonesia. (2009). Batas Maksiumum Cemaran Logam Berat dalam Pangan. SNI: 7387-2009. Badan Standardisasi Nasional, Jakarta.

Turek, A., Wieczorek, K., and Wolf W.M. (2019). Digestion Procedure and Determination of Heavy Metals in Sewage Sludge-An Analytical Problem, Sustainability, 11: 1753-1763. Retrieved from https://doi.org/10.3390/su11061753

Vinas, P., M. Pardo-Martinez \& M. Hermandez-Cordoba. (2000). Rapid Determination of Selenium, Lead and Cadmium in Baby Food Samples Using ETAAS and Slurry Atomization, Anal. Chim. Acta, 412, 121-130. Retrieved from https://doi.org/10.1016/S0003-2670(00)00758-3

Yaman, M., Y. Dilgin \& S. Gucer. (2000). Speciation of Lead in Soil and Relation with Its Concentration in Fruits, Anal. Chim. Acta, 410, 119-125. Retrieved from https://doi.org/10.1016/S0003-2670(99)00895-8

Zong, Y.Y., P.J. Parsons \& W. Slavin. (1996). Accurate and Precise Measurements of Lead in Bone Using

Zhong Wen-Si, Ren T., and Li-Jao Zhao. (2016). Determination of Pb (Lead), Cd (Cadmium), Cr (Chromium), Cu (Copper), and Ni (Nickel) in Chinese tea with high-resolution continuum source graphite furnace atomic absorption spectrometry, Journal of Food and Drug Analisis, 24: 46-55. Retrieved from https://doi.org/10.1016/j.jfda.2015.04.010 